Article

\title{
Same Same but Different? Gender Politics and (Trans-)National Value Contestation in Europe on Twitter
}

\author{
Stefan Wallaschek ${ }^{1, *}$, Kavyanjali Kaushik ${ }^{2}$, Monika Verbalyte ${ }^{1}$, Aleksandra Sojka ${ }^{2}$, Giuliana Sorci ${ }^{3}$, \\ Hans-Jörg Trenz ${ }^{3}$, and Monika Eigmüller ${ }^{1}$ \\ ${ }^{1}$ Interdisciplinary Centre for European Studies, Europa-Universität Flensburg, Germany \\ ${ }^{2}$ Department of Social Sciences, Universidad Carlos III de Madrid, Spain \\ ${ }^{3}$ Faculty of Political and Social Sciences, Scuola Normale Superiore, Italy \\ * Corresponding author (stefan.wallaschek@uni-flensburg.de)
}

Submitted: 30 July 2021 | Accepted: 11 November 2021 | Published: 17 February 2022

\begin{abstract}
The progress achieved in women's rights and gender equality has become the target of a backlash driven by "anti-gender" activists and right-wing populists across EU member states. To a large extent, this conflict takes place in the digital and social media spheres, illustrating the new mediatized logic of value contestation. Therefore, we ask to what extent are the debates about gender equality on Twitter similar in three European countries, and how do users engage in these debates? We examine these questions by collecting Twitter data around the 2021 International Women's Day in Germany, Italy, and Poland. First, we show that the debate remains nationally segmented and is predominantly supportive of gender equality. While citizens engage with the gender equality value online, they do so in a prevailingly acclamatory fashion. In contrast, political and societal actors show higher levels of engagement with the value and receive more interactions on Twitter. Our study highlights the relevance of national contexts to the analysis of (transnational) social media debates and the limited political engagement of citizens on Twitter across Europe. We also critically discuss the strengths and weaknesses of a cross-country social media comparison.
\end{abstract}

\section{Keywords}

gender equality; Germany; international women's day; Italy; Poland; Twitter; value conflicts

\section{Issue}

This article is part of the issue "Analyzing Citizen Engagement With European Politics Through Social Media" edited by Pieter de Wilde (Norwegian University of Science and Technology), Astrid Rasch (Norwegian University of Science and Technology), and Michael Bossetta (Lund University).

(C) 2022 by the author(s); licensee Cogitatio (Lisbon, Portugal). This article is licensed under a Creative Commons Attribution 4.0 International License (CC BY).

\section{Introduction}

The European Union (EU) portrays itself as a "community of values," with gender equality being one of the core elements of such self-image. Over the last two decades, gender mainstreaming and anti-discrimination policies have expanded in the EU and all its member states (Akaliyski et al., 2021; Pollack \& Hafner-Burton, 2000). At the same time, the feminist movement gained new ground through online public mobilization. One example is the \#MeToo movement that resonated in various countries, creating a heated public debate about sexual assault and the persistent patriarchal character of societal structures. Other gender equality issues highlighted through online campaigns include the gender pay gap as well as increasing awareness that women experience more hate speech and uncivil behaviour on social media than men (Jackson et al., 2020; Willem \& Tortajada, 2021). Nevertheless, the backlash against women's rights has also gained traction, with new movements opposed to the so-called "gender ideology" emerging all over Europe. The impacts of such counter-mobilization include bans on academic 
programs in gender studies in Hungary, further restriction of abortion rights in Poland, and attacks against feminists growing stronger in many member states (Kaiser, 2020; Righetti, 2021). Hence, gender equality and antidiscrimination policies remain one of the most heavily contested policy areas (Kuhar \& Paternotte, 2018; Verloo \& Lombardo, 2007).

Against this background, we explore Twitter debates on gender equality in Germany, Italy, and Poland. We ask two main research questions: (a) To what extent are the debates about gender equality on Twitter similar in the three countries? And, further: (b) How do Twitter users engage in these gender equality debates, and to what extent do we observe different interactions, such as likes or retweets, for more or less engaging tweets? To answer the first question on the structure of the Twitter debate, we analyse the co-occurrence of hashtags across the three cases and examine discourse networks in each country. Regarding the second question, we develop a typology of online engagement and investigate these different types in the respective countries and how they intersect with Twitter interactions (retweets, likes, replies, or mentions).

We select Twitter as the platform best suited for public engagement in political debates where pro-gender equality campaigning is likely to converge (e.g., around international hashtags), and opposing views are also likely to find expression. Moreover, due to its character as a rather elite social media network (Stier et al., 2018), public debates of women's rights on Twitter might affect the political sphere because politicians, civil society actors, and other key stakeholders actively follow and engage in these debates. To select a period in which gender equality issues gain public attention, we focused on the days before and after the 2021 International Women's Day (IWD; March 1 to March 10). The IWD constitutes a global public event focused on the fight for women's rights and a more just society for all genders. Institutionalized in 1911, it marks a central date of the women's movement for organizing demonstrations and raising awareness for diverse gender equality-related issues. Since large rallies and marches characteristic of IWD could hardly occur in 2021 due to the Covid-19 pandemic, online mobilization and debates have become even more relevant. Such heightened public attention may provide an opportunity for not only a plurality of individual and collective actors to affirm their support for gender equality but also for "anti-gender" activists to try to reframe the debate. Hence, our study is less concerned with the specificities of the IWD (campaign) and instead utilises this chosen period as a possible impulse for online debates on gender issues.

Our article makes three main contributions. First, we show that Twitter debates on gender issues remain nationally segmented and depict only weak patterns of transnationalization in terms of the topics raised. While the public debates are mainly pro-gender equality, we also illustrate that "anti-gender" discourses can be found across all three online public spheres. Secondly, based on manual coding of the representative sample of randomly selected tweets, we demonstrate that citizens strongly engage in the social media debate during the chosen period, but in a less political and more acclamatory way than political representatives and media actors. Finally, we highlight the Twitter affordances in order to explain that strong public engagement of citizens does not automatically translate into high visibility and reach. In terms of the number of Twitter interactions, Twitter users with an institutional affiliation or celebrities receive more attention than regular citizens.

\section{Gender Equality and Citizen Engagement on Social Media}

\subsection{Feminist Activism on Social Media}

Women's rights and feminist issues have become heavily politicized in recent years (Kováts, 2017). The \#MeToo movement is perhaps the most powerful example of a successful global feminist mobilization in the digital age. The campaign criticized sexual harassment and assault in the workplace and spotlighted the unequal position of women in public life more broadly. Moreover, many European countries also experienced online and offline mobilization on domestic violence, abortion rights, or traditional gender stereotypes, among other issues. These campaigns raised awareness on the individual instances of injustices and discrimination faced by women. Together, such interventions on social media created social pressure to put different aspects of gender equality on the political agenda (Jackson et al., 2020). Facing fewer organizational barriers while creating safer online spaces for women to share their stories, digital feminist activism has become a central element of gender equality mobilization (Scharff et al., 2016; Willem \& Tortajada, 2021). Examples of such "hashtivism" include \#MeToo, the German hashtag \#Aufschrei on sexual harassment and sexist comments, or the Polish \#czarnyprotest that mobilized against the abortion ban (Drüeke \& Zobl, 2016; Jackson et al., 2020). Thus, gender and feminist issues mobilize across countries and receive public attention. The IWD as a widely publicized event might enable actors to articulate these issues on Twitter in a condensed period of time.

However, these campaigns and the involved actors also experience severe public and even physical attacks by "anti-gender," right-wing, and religious actors and movements (Kaiser, 2020; Kuhar \& Paternotte, 2018). They accuse feminists of being "feminazis," degrade progender equality positions as "gender ideology" and use hate speech and transphobic claims in their public communication (Korolczuk \& Graff, 2018; Righetti, 2021). Hence, these actors might use the public attention to women's rights created by the IWD to mobilize against gender equality issues in general, verbally attack opponents, or interpret the movement for equal rights among 
all genders with conservative frames. Furthermore, in all three countries, right-wing parties represented in parliament or/and the government-Italian Lega and Fratelli d'Italia, the Polish Prawo i Sprawiedliwość (PiS; Law and Justice), and the German Alternative für Deutschland (AfD)-are mounting attacks on what they call "gender ideology." In particular, right-wing actors are highly active on social media platforms. They use these to communicate to their sympathizers directly, circumventing the legacy media and establishing transnational links among right-wing organizations across Europe (Froio \& Ganesh, 2019; Knüpfer et al., 2020). In sum and against the backdrop of the IWD as a transnational digital event that brings women's rights to the forefront of the public debate, we expect high visibility of institutionalized actors such as political parties and social movements and activists in all three cases, both defending and opposing gender equality issues.

Concerning issue visibility, we consider the Covid-19 pandemic a strong contextual factor that may lead to the convergence of the Twitter debate in these countries. Women are particularly affected by the health crisis because they work more often than men in the health and service-oriented sectors (e.g., elderly care, education institutions) and thereby have a higher risk of getting infected. Since women also predominantly take over care responsibilities in the family, they experience more (mental and physical) stress at work and home, while men tend to prioritize their paid work and their future in the labour market (Czymara et al., 2021; Zoch et al., 2021). Moreover, recent initiatives to tighten abortion laws in Poland, court convictions of gynaecologists who provide information on abortion in Germany, and the influential role of the Catholic Church in debates on abortion in Italian politics, created attention to women's reproductive rights that might be taken up by various actors in the context of the 2021 IWD. Another issue that is expected to resonate across countries is the persistent unequal pay and women's access to the labour market. Due to the low wages in care-intensive jobs and dominance of part-time employment for women, (female) Twitter users might share their experiences, point out discriminatory work policies, and call for better pay and equal treatment in the labour market. Due to the pandemic circumstances around the IWD 2021, we expect that care and health issues are articulated and receive (transnational) attention on Twitter. Moreover, we expect that abortion and unequal payment are issues that are raised in all three countries.

\subsection{Online Engagement}

Some scholars argue that with the advent of digital and social media in the late 2000 s, the contestation of fundamental values has become more salient in the public sphere. Social media platforms are less regulated in terms of access and spreading information than traditional media sources. Societal and political actors can use these digital channels to shape public opinion and disseminate their ideas-even if this includes illiberal and anti-democratic claims, spreading disinformation, and spurring dissatisfaction with democratic principles (Miller \& Vaccari, 2020; Tucker et al., 2017). However, political conflicts and value contestation are not only amplified through social media in a way to gain salience and impact public opinion. The social media platforms also constitute an independent arena of value contestation and activate a variety of actors who engage in value conflicts and use the new digital affordances for political expression and mobilization (Hjarvard et al., 2015). Relying on the literature of social media political engagement (Bossetta et al., 2017; Dahlgren, 2013; Givskov \& Trenz, 2014), we can expect that, on the one hand, events such as the IWD are meant as a celebration of values and remembrance of solidarity among women. On the other hand, they are seen as opportunities to express a critique of discrimination and to mobilize for political change.

In particular on Twitter, new forms of hashtag activism have developed to raise awareness and give voice to marginalized (minority) communities (Jackson et al., 2020). Hashtags can be used in an acclamatory way to unite the users in celebration of values or in a politicized way, to position them in support or opposition of values. How these different levels of engagement resonate on Twitter regarding the number of likes, retweets, or replies for more or less engaging tweets is not addressed in previous studies so far (see also de Wilde et al., 2022). In this study, we distinguish between five different levels of engagement on Twitter beyond the use of hashtags and expect users to (a) relate to the value in a celebratory way without explicit reference to its underlying values, responsibilities or solutions; (b) to contribute to the Twitter debate through the sharing of factual information and non-opinionated statements on gender equality; (c) to raise moral arguments with reference to underlying values, to identify cases of discrimination and violation of rights, and to express criticism of the insufficiencies of existing provisions of gender equality; (d) to call for action in support or opposition of values; or (e) to target political opponents in a way that ascribes responsibility for discrimination and violations of gender equality and calls for political change. While we inductively explore the different levels of engagement in our data, we have two expectations on their relationship: There will be fewer tweets that have a higher political engagement level. Moreover, we expect that the higher the engagement level for a tweet, the higher the number of interactions for this tweet.

\subsection{Gender Equality in Poland, Germany, and Italy}

Previous studies on the women's movements and the contestation of gender issues across Europe point out that the national context powerfully shapes the actor constellation and issue attention in each country (Köttig 
et al., 2017; Kuhar \& Paternotte, 2018). While our study does not aim to trace the historical legacies of the women's movement or examine changing political cultures in these countries, we consider them as important contextual factors that help us account for national differences.

The EU institutionalized gender equality and created a supranational reference space for these issues in the national politics of member states. However, despite such convergence, most equality norms included in the legally binding EU documents and jurisprudence address rights within the labour market, such as equal access to employment or education (Cichowski, 2013; Wobbe \& Biermann, 2009). Women's rights not directly related to non-discrimination are not inscribed in the treaties and therefore cannot be as effectively defended by the EU. Such divergence across the EU member states is perhaps the most striking in terms of reproductive rights. Since these less institutionalized gender issues seem to be the ones that also produce most of the current debates, cultural variation between countries in acceptance of gender equality values and feminist discourse may account for country differences in our analyses.

In our sample, we include two founding EU member states-(West-)Germany and Italy-and one more recent member state, Poland. Based on the Gender Equality Index (European Institute for Gender Equality, 2020), all three countries belong to the lower half of the European distribution in terms of gender equality, yet Germany ranks higher than the other two countries in terms of equal access to political power, education, and labour market. Furthermore, they also have different cultural, political, and feminist traditions. Germany has a strong Protestant background favourable to emancipative values, Italy is predominantly Catholic, and Poland is both Catholic and a post-communist country, which has important implications for country differences in views on gender roles (Akaliyski \& Welzel, 2020). Eastern Germany presents a more liminal case: Since the German Democratic Republic (GDR) has been under communist rule, the Eastern part of Germany still shows lower approval of gender equality (Gerhards, 2014).

IWD traditions also differ across these countries. Historically, international impulses have played an important role in feminist mobilization, and the IWD experienced a significant increase in global relevance, such as the UN's decision in 1977 to celebrate March 8 as a day for women's rights and world peace. However, the countries' traditions of IWD celebrations vary. For Germany, the East-West divide still matters in shaping political mobilization. The IWD in the GDR was an official stateled celebration and a holiday since the end of the 1940s. In West Germany, however, it was not until the protests over the abortion paragraph $\$ 218$ and the leftwing social movements gaining influence at the end of the 1960s that demonstrations on March 8 took place. Recently, new forms of digital feminist activism regarding reproductive rights, equal representation of women, and sexual harassment have gained public attention. Italy was one of the first countries to relaunch March 8 celebrations after World War II, supported by the influential trade union movements and the leftist UDI (Union of Italian Women). This explains an historically high politicization of the feminist and protest movements in their fight against patriarchy and traditional family roles. Recently, domestic violence and the right to abortion became crucial issues in the Italian women's movement Non Una di Meno and the IWD in particular. The Polish legacy of the IWD shares the historical experience of the GDR in terms of the relatively apolitical communist state-celebration of this day. Under communism, giving flowers and small gifts to women had become a prevalent manner of celebrating March 8, accompanied by official praise of women in the workforce. Currently, the day is largely devoid of such influence and constitutes a more generic celebration of women in general and, often, of traditional femininity. At the same time, the IWD is also celebrated as Women's Rights' Day in Poland. The country has seen a recent rise in women's political mobilization in defence of their rights due to the government's intent to further limit abortion rights on September 2016. A prominent example is the feminist social movement Ogólnopolski Strajk Kobiet (Polish Women's Strike). Thus, the IWD 2021 has also been marked by marches against the limitation of abortion rights.

Given these country differences, the selected cases allow us to formulate the following expectations regarding their relevance for the citizens' engagement in online debates on gender equality. In Poland, we expect to see the lowest level of engagement in the public due to the apolitical women's movement tradition and comparatively lower societal support for gender equality. Only political actors or activists would be more engaged around anti-gender or reproductive rights' issues. In Italy, the vivid protest culture and recent feminist mobilization might engage more people than in Poland, mainly around the issues of domestic violence and abortion rights. But, yet again, the public will probably be less engaged in the conversation, with political and societal actors taking the lead. Germany might show the highest level of engagement for gender equality on Twitter. While feminist issues in Germany are not strongly politicized, the public support for gender equality is high. Thus, if people publicly engage on Twitter, they might be the ones who truly care about gender equality and may also express criticism or demands. In the German case, we, therefore, expect that various gender equality issues gain similar attention on Twitter.

\section{Collecting and Analysing Twitter Data in Three Countries}

The analysis of national Twitter debates aims to capture country-specific discourses for comparative purposes. Collecting Twitter data is per se a transnational and predominantly English language-oriented endeavour, which 
is why previous studies have looked at widely shared English hashtags (\#MeToo or \#RefugeesWelcome) or hashtags with an inherent transnational scope such as \#TTIP or \#climatechange (Knüpfer et al., 2020; Ruiz-Soler, 2020; Schünemann, 2020). Thus, by selecting the period around the IWD, we look at a transnational event that favours the appearance of gender equality issues on Twitter which might nonetheless be framed according to national politics and political culture in Germany, Italy, and Poland.

A recurrent challenge of collecting tweets for comparative analysis is that we cannot rely on Englishlanguage terms and instead need multilingual terms in German, Italian, and Polish. Besides consulting the relevant literature on the women's movement and anti-gender campaigns (among others Kuhar \& Paternotte, 2018), this required the authors, who are fluent in the languages of our three country cases, to manually search for hashtags and keywords frequently employed in gender equality tweets in their respective countries, along with several translations of common phrases related to "equal rights," "feminism," and "gender ideology" (see the Supplementary File for the full list of keywords). We employ keywords in national languages rather than hashtags to collect the data because they allow us to identify a broad set of tweets and actors. While hashtags are widely used for social media data collection and analysis, their usage implies a certain level of digital literacy because it is considered "a digital linguistic practice" (Heyd \& Puschmann, 2017, p. 5) and an intentional act to link the tweet to a broader public debate on a certain issue. However, Twitter users -in particular non-institutionalized actors-might share their views on gender equality issues without using the official announced IWD hashtags (\#IWD2021; \#ChooseToChallenge) or hashtags at all. The use of geolocation filters for country-specific sampling is equally problematic as only a minority of users add locations to their tweets (Schünemann, 2020). Hence, we built a search query on the Twitter v2 API to collect the data without a geo-location filter as well as using important hashtags-without the hashtag symbol-and countryspecific keywords associated with the main IWD event and gender equality during the period of March 1 to March 10, 2021. After collecting the data, we semiautomatically discarded duplicates. Based on given location information in the Twitter user's bio (wherever provided), we deleted tweets that did not belong to the German, Polish, or Italian context (i.e., tweets from Austria in German language). In total, we collected 52,785 tweets (17,007 German, 22,913 Italian, and 12,865 Polish).

Figure 1 provides an overview of our data. The trajectories are comparable across countries, with a short period of warm-up and mobilization culminating on the IWD on March 8. The following day shows post-IWD tweets in the three countries, but the number of tweets drops significantly. The number of tweets from Italy is almost consistently higher than in the two other cases, while Poland shows the lowest number of tweets in this period (see Table A1 in the Supplementary File for tweet volume per day in each country).

In order to answer our questions on the structure of the Twitter debates and the levels of engagement, we

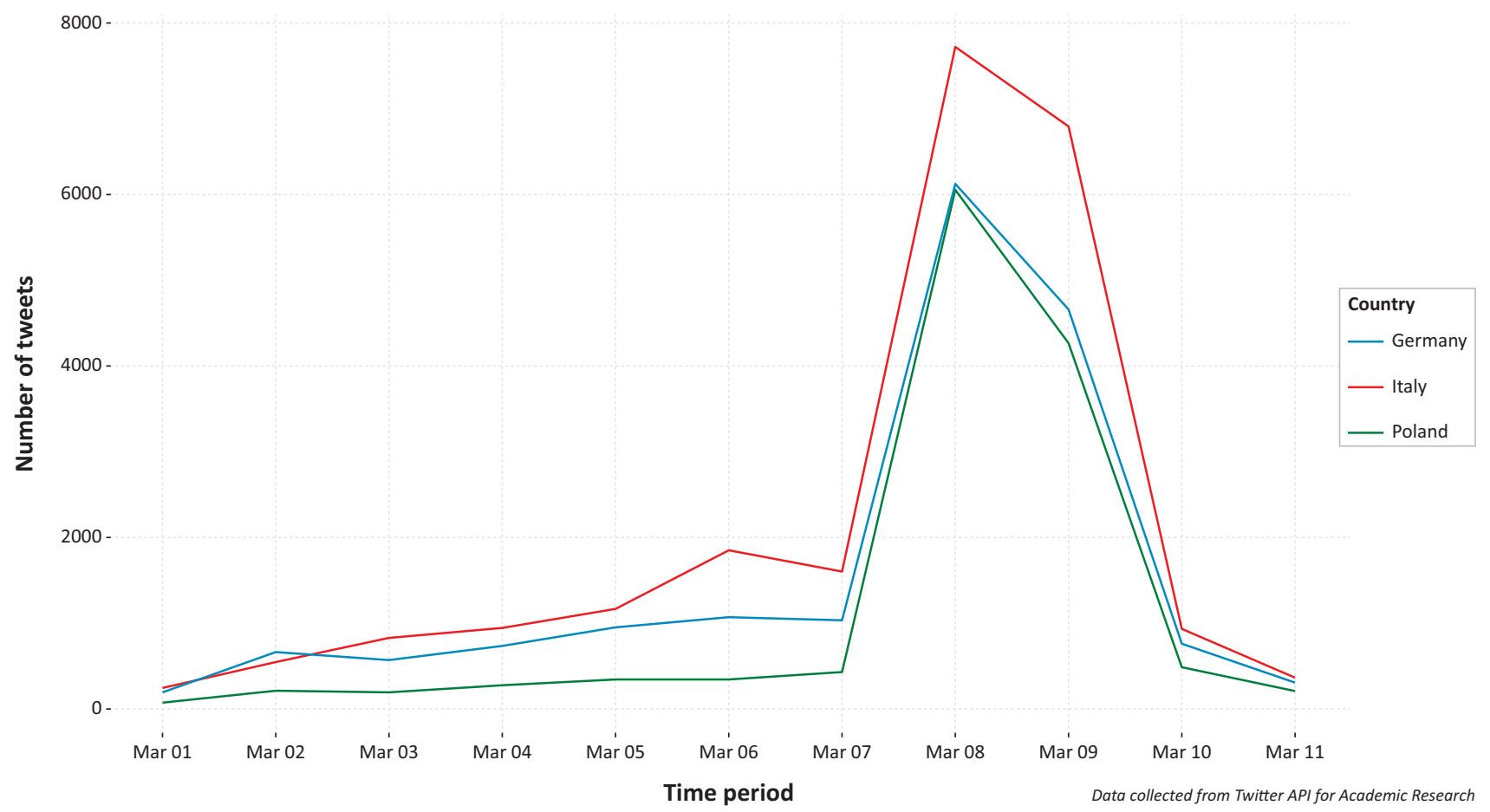

Figure 1. Number of German, Italian, and Polish tweets (March 1 to March 10, 2021). Note: Number of tweets = 52,785 (17,007 German, 22,913 Italian, and 12,865 Polish). 
use various measures. First, we rely on co-occurrence analysis of hashtags (a pair of hashtags appearing together in a single tweet) to identify which topics on gender equality have the most resonance around IWD and whether there exists any transnational linkage. Looking for transnational patterns in retweets to establish convergence or divergence in issue salience has been rare outside English tweets due to language, geographical, and socio-political variation among countries (Froio \& Ganesh, 2019; Ruiz-Soler, 2020). Therefore, we check for similarities or dissimilarities through a co-occurring hashtag network that allows for a more robust comparative analysis, looking for common patterns in discourses rather than retweets' metadata. Out of the 52,785 total tweets, 20,462 (39\%) contained 18,555 unique hashtags, with an average of 2.87 hashtags per tweet. Our extraction of these tweets with the $\mathrm{R}$ package quanteda (Benoit et al., 2018) showed that $46 \%$ were German, $42 \%$ Italian, and $12 \%$ were Polish.

Using the 30 most frequently occurring hashtag pairs (see Table A5 in the Supplementary File for the complete list), we construct a co-occurrence network, whose nodes are represented by the hashtags, and the weighted edges between them are set according to the frequency of the co-occurrence of two hashtags in unique tweets. The betweenness centrality measure is applied to scale the size of the nodes, with larger nodes representing higher values. In our case, betweenness centrality is useful for identifying those hashtags that lie on the shortest path connecting two other hashtags. That tells us which topics act as bridges connecting two otherwise disparate topics. A node (hashtag) with high betweenness centrality has a large outreach on the network since it effectively connects different network regions. The official IWD hashtags will likely have large centralities in this case, but the use of these hashtags with other gender equality hashtags can reveal how the Twitter users in the three different national contexts tweet about this value. We used the software Gephi (Bastian et al., 2009) to build the network and detect communities of hashtags. Gephi's Louvain clustering algorithm (Blondel et al., 2008) detects smaller communities within the larger network, with higher modularity scores indicating denser clusters. Nodes (hashtags) clustered within smaller communities have more information flows between them than their flows with nodes outside the communities.

Next, we took a random sample of $2 \%$ of all tweets per country and coded them manually (341 German, 459 Italian, and 267 Polish tweets). These samples guarantee reliable results (at the 0.05 margin of error and $90 \%$ to $96 \%$ confidence intervals). Our codebook (in the Supplementary File) captures five main categories: level of engagement, position (pro, neutral, or contra-gender equality), actor type (individual or collective), actor affiliation, and issue (up to three issues to be selected from an open list). The unit of analysis is a single tweet. Coding was developed by five trained coders in their native lan- guages. After three rounds of coder training (with English language tweets from Ireland) and several adaptations to the codebook to accomplish an intersubjective understanding of the codes, we reached intercoder reliability across the coded categories of 0.76 (Fleiss' Kappa) with the lowest score of 0.64 for levels of engagement and the highest of 0.88 for actors. While we see these results as satisfactory, we expect that the reliability may be higher in the country-specific datasets due to the better knowledge of the coders of each national context. Tables A8 to $A 15$ in the Supplementary File summarize the data for each country case and the main code categories.

We apply the discourse network methodology (Leifeld \& Haunss, 2012; Wallaschek et al., 2020) to the manually coded tweets' dataset. Our objective is to examine how actors and issues are linked in the three Twitter debates and whether there are any discursive patterns across the different national contexts. This method was predominantly developed to examine policy discourses in newspaper articles and policy documents by identifying ideational linkages and discourse coalitions (Leifeld, 2016), while the analysis of social media discourse networks has only recently received scholarly attention (Bossner \& Nagel, 2020). For each country, we use a two-mode network structure, consisting of actors (political, societal, economic, media, influencer, citizen, and other), the issues they raised, and the position they hold on these issues. We use betweenness centrality as a measure to identify those nodes, i.e., actors and issues that link different sub-discourses on gender equality and guide the flow of information via their existence as influential bridges. In two-mode networks such as ours, betweenness centrality is the function of paths from actors to actors, from actors to issues (or issues to actors), and from issues to issues with the scores implying a certain exclusivity of an actor or an issue, since a node is only central as long as it is the only node in its vertex-set (Borgatti \& Everett, 1997, p. 256).

\section{Results}

The following section is structured along our two research questions and formulated expectations in Section 2. First, we look at the co-occurring hashtags in the overall Twitter discourse on gender equality in three countries to investigate transnational linkages. Second, based on the coded sample data, we present discourse networks of actors and issues in three countries to provide a more in-depth look at the debate on gender equality. Finally, we show the levels of engagement and how they differ regarding the interactions.

\subsection{Co-Occurring Hashtags in Nationally Segmented Twitter Debates}

To establish how issues on gender equality relate to each other, we examine the co-occurrences between a pair of hashtags. Figure 2 shows the co-occurrence 


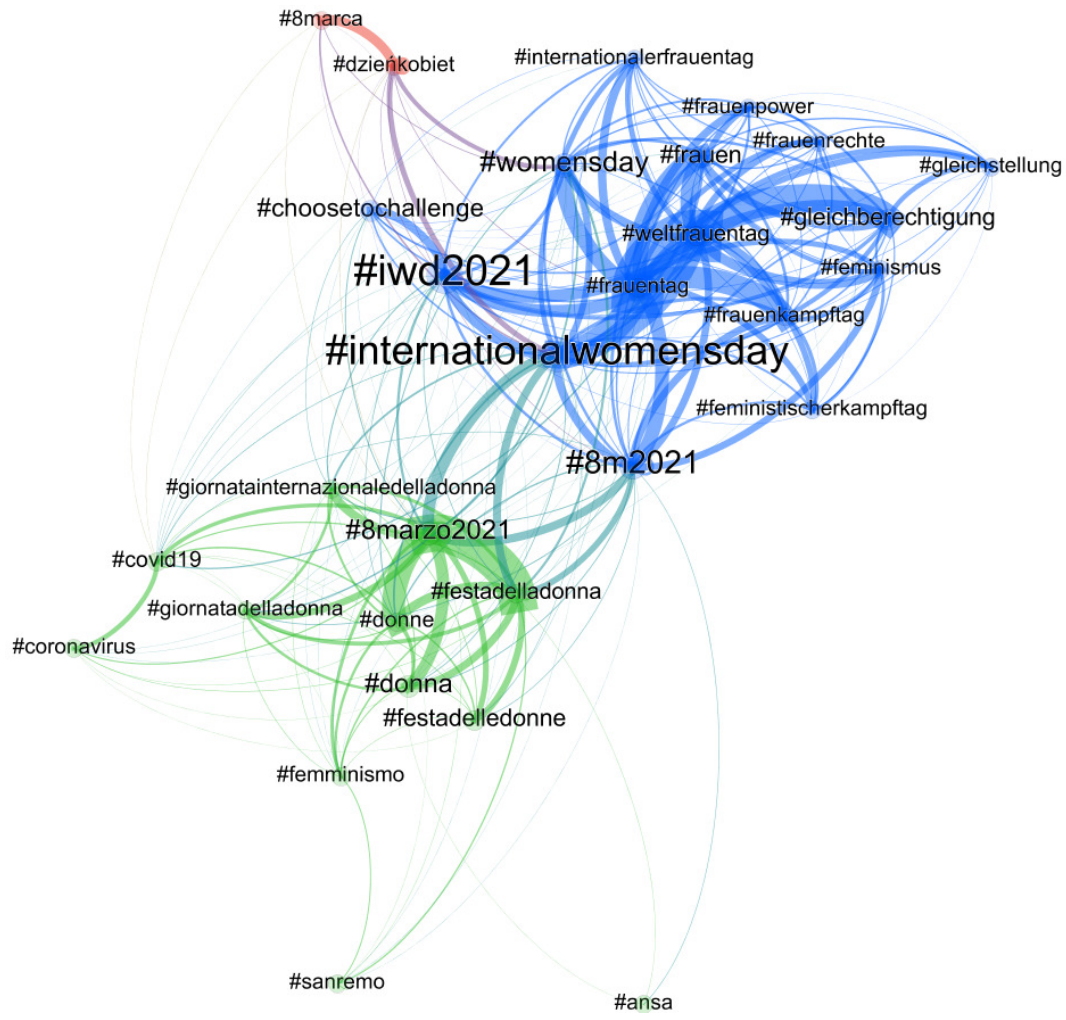

Figure 2. Co-occurrence network of top 30 hashtags from Germany, Italy, and Poland. Notes: Node size is based on betweenness centrality; blue indicates the German hashtag cluster, while green and red show the Italian and Polish hashtag clusters, respectively; the network is based on the Force Atlas layout algorithm in Gephi.

patterns between the most frequently used hashtags during the mobilization period of March 1 to March 10, 2021. Twitter debates on IWD remain nationally segmented: The applied modularity measure (Modularity score: 0.306) detected three communities of hashtags: German, Italian, and Polish clusters (Table A5 and A6 in the Supplementary File summarize the centrality scores and community structure of the hashtags). English campaign hashtags provide important linkages between the national clusters of German (blue), Italian (green), and Polish (red) hashtags. The main campaign hashtags \#iwd2021 and \#internationalwomensday reported the highest betweenness centrality of 36.05 and 32.94 (for all scores, see Table A6 in the Supplementary File). Yet, except for these popular hashtags, there is a substantial variation in how users in the three countries employ hashtags to tweet on gender equality and the IWD.

In Germany, users link the international IWD hashtags to value-oriented hashtags such as \#gleichberechtigung (equal rights), \#feministischerkampftag (feminist day of struggle), or \#frauenpower (women's power). In Italy, IWD hashtags are employed less diversely and predominantly focus on the event itself. The use of the hashtag \#festadelladonna (\#celebratingwomanday) gives voice to those women who complain about a mere celebratory activity on this day and reclaim it to fight for women's rights. Moreover, in the Italian case, IWD is linked to Covid-19 hashtags (\#covid19, \#coronavirus), highlighting the pandemic's impact in Italy. In Poland, the use of hashtags on gender equality with hashtags of IWD campaign is the lowest when compared to Germany and Italy, and remains primarily limited to linking celebratory hashtags such as \#dzieńkobiet (women's day) with \#iwd2021 or \#internationalwomensday. This indicates that on this strategic event, IWD tweets in Germany and Italy were more likely to co-occur with hashtags on equal rights, health, and feminism, while this trend was missing in Poland, where IWD hashtags tended to co-occur with acclamatory hashtags.

\subsection{Discourse Networks in Germany, Italy, and Poland}

To better understand which actors raise what types of issues related to gender equality and IWD, we look at the weighted two-mode networks of actors and issues. Figures 3,4 , and 5 show that, overall, users in all three countries tweeted in support of gender equality indicated by the prominent green edges running from actors to issues. The most central actors in all three countries were citizens (betweenness centrality scores for all nodes in the networks in Table A7 in the Supplementary File). This implies that citizens are the main connectors between different issues and, thus, have a large influence in the flow of the discourse on gender equality, followed by political, economic, and media actors. Therefore, our expectation that institutionalized actors would occupy the most central positions is not supported. Moreover, the high centrality of citizens in all 
three cases challenges the typical perception of Twitter as an "elite social media network" to some extent. However, the number of issues raised (issue nodes in blue) by the six types of actors (actor nodes in orange) varied considerably in the three networks, with German actors tweeting about 30 different issues, followed by Italian and Polish actors who tweeted on 21 and 20 different issues, respectively.

As illustrated by the dense network of issues and actors (Figure 3, Density: 0.16), the German discourse predominantly engages positively with various gender equality issues. The core themes are equal rights, empowerment, feminism, and patriarchy, used by various actors, while issues such as abortion rights, health and care, or hate speech remain at the periphery. Citizens remain rather acclamatory by tweeting "Happy international women's day" without reference to values or issues, which indicates an apolitical engagement among ordinary people. German political actors campaigned more actively to support gender equality issues such as equal pay or feminism-compared to political actors in Italy and Poland-while also opposing LGBTQI* rights and employing the conservative narrative of "gender ideology." For instance, a local AfD politician criticized the diversity policies of the governing coalition in Hamburg, calling it "rot-grüne Genderwahn" (red-green gender mania). Going against our expectation, abortion rights and healthcare issues fail to attract much mobiliza- tion, but equal pay, as expected, is raised by citizens, economic, media, and political actors alike.

Despite the highest number of tweets during the entire period, the Italian network (Figure 4, Density: 0.19 ) is less varied in terms of contested issues than the German network but more active than the Polish network. Citizens tweet largely in support of the general themes of equal rights and feminism, but as other Italian actors, all engage in a rather celebratory way without referring to any specific issue. Interestingly, only citizens and influencers seem to oppose gender equality in their tweets by employing the "gender ideology" narrative and traditional gender roles stereotypes; other actors in the Italian network remain supportive or stay neutral to gender equality. Media and economic actors in Italy engage quite strongly in the Twitter debate, but as citizens, they seem more reluctant in propagating the value of gender equality and often display only low engagement in a celebratory way. When they engage beyond acclamation, they support equal rights or criticize domestic violence in their tweets. Moreover, and as in the German case, abortion rights and healthcare issues fail to gain the spotlight, but the issue of equal pay invites supporting tweets from economic, media, and to a certain extent, political actors.

The most loosely connected network is that of Polish actors and issues (Figure 5, Density: 0.15). Again, citizens are the most influential nodes of the network.

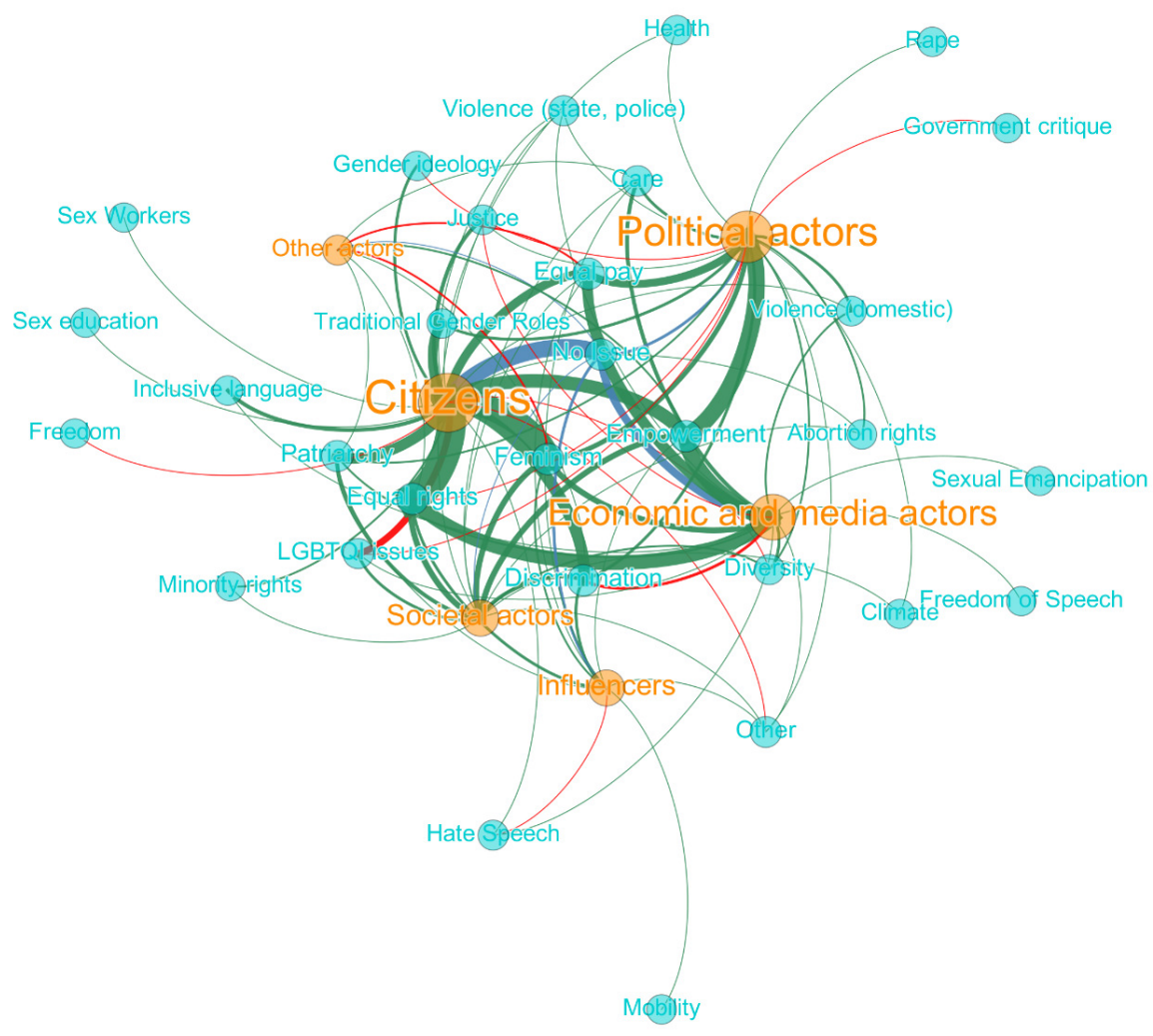

Figure 3. Issue-actor network of tweets from coded German sample. Note: The bipartite graph depicts two nodes-issues (blue) and actors (orange)-and the relationship between them through the weighted edges with different position stands (Pro: Green, Neutral: Dark Blue, Contra: Red). 


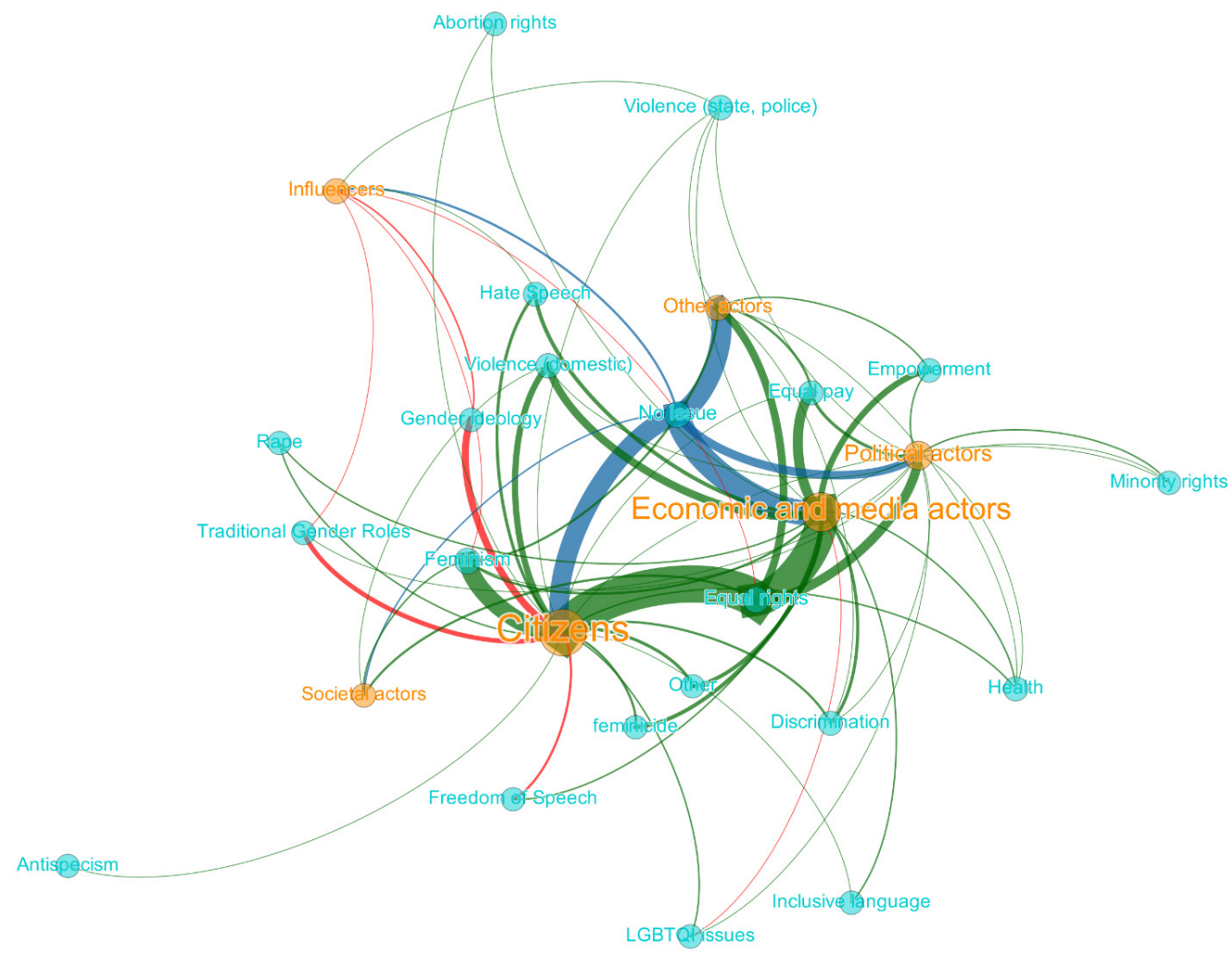

Figure 4. Issue-actor network of tweets from Italy. Same graph description as in Figure 3.

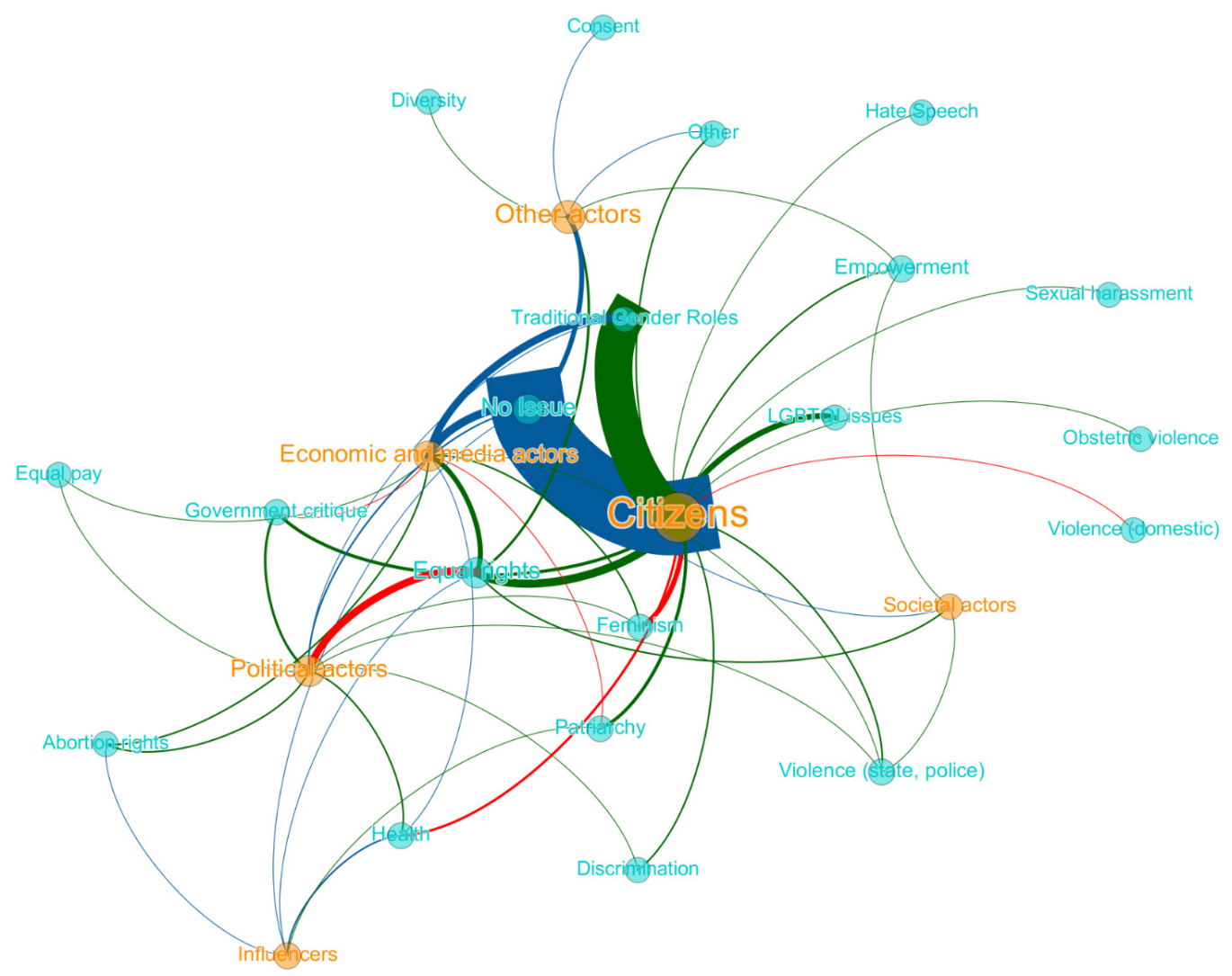

Figure 5. Issue-actor network of tweets from Poland. Same graph description as in Figure 3. 
However, they are less likely to tweet about any particular issue. Instead, they primarily post celebratory tweets on the occasion of women's day, offering generic praise of women and frequently mentioning giving or receiving traditional flowers, visualized by the two thickest edges between citizens and "no issues" and citizens and "traditional gender roles." Moreover, political, economic, media, and other societal actors also refrain from participating actively in the discourse on women's rights. When they do, they either remain neutral or post generically supporting "equal rights" tweets. Despite the controversial judicial decision that implied an effective ban on abortion rights in 2020 and organized demonstrations in the streets of major cities on March 8, 2021, the citizens, societal, and political actors in our sample hardly tweeted about the issue of gender equality. Against our expectations, equal pay and healthcare issues also fail to mobilize actors in the discourse network. Positive mentions of LGBTQI* issues by citizens highlight the contrast between the government-led campaign against LGBTQI* rights, absent in our analysis, and the citizen's discourse.

In all three cases, a transnational pattern against the value of gender equality emerged on the two issues of feminism and "gender ideology." Actors who tweeted against the value employed the narrative of gender ideology to criticize or undermine the feminist movement. However, in Germany, it was either far-right politicians or far-right actors at the periphery of the network who attacked feminism by holding a conservative understanding of the feminist movement and questioning the diversity of opinions on feminism and gender. In Italy and
Poland, on the other hand, citizens engaged against the value of gender equality by employing anti-gender discourse or stereotypical frames.

\subsection{Levels of Engagement on Twitter}

We now turn to the level of engagement in the three countries based on the manual coding of the tweets. Low engagement levels prevail in the collected tweets (Germany: $29.9 \%$; Italy: $32.4 \%$; Poland: $66.6 \%$ of our sample; see Table A11 in the Supplementary File). The Polish debate, in particular, shows a strong tendency towards an apolitical perception of this day which might be a legacy of the former communist state-led celebrations on March 8. Underlined is this weak politicization of the IWD when we look at the number of tweets that highly engage with gender equality. The highest level of engagement was identified in only $3.1 \%$ of all Polish tweets, while the German case shows $7.3 \%$. Hence, our expectations on the different levels of engagement in our three countries-Poland showing the lowest, and Germany the highest levels of engagement-are generally supported.

The low level of engagement in the tweets also affects how users interact with them. In Figure 6, we compare the levels of engagement with the average response to a tweet regarding the number of likes, quotes, replies, and retweets. It shows that receiving likes is the most common engagement from users with a tweet in all three cases, but also the one that creates the least public attention. Quoting or retweeting other tweets increases the audience to this particular tweet, while liking a tweet

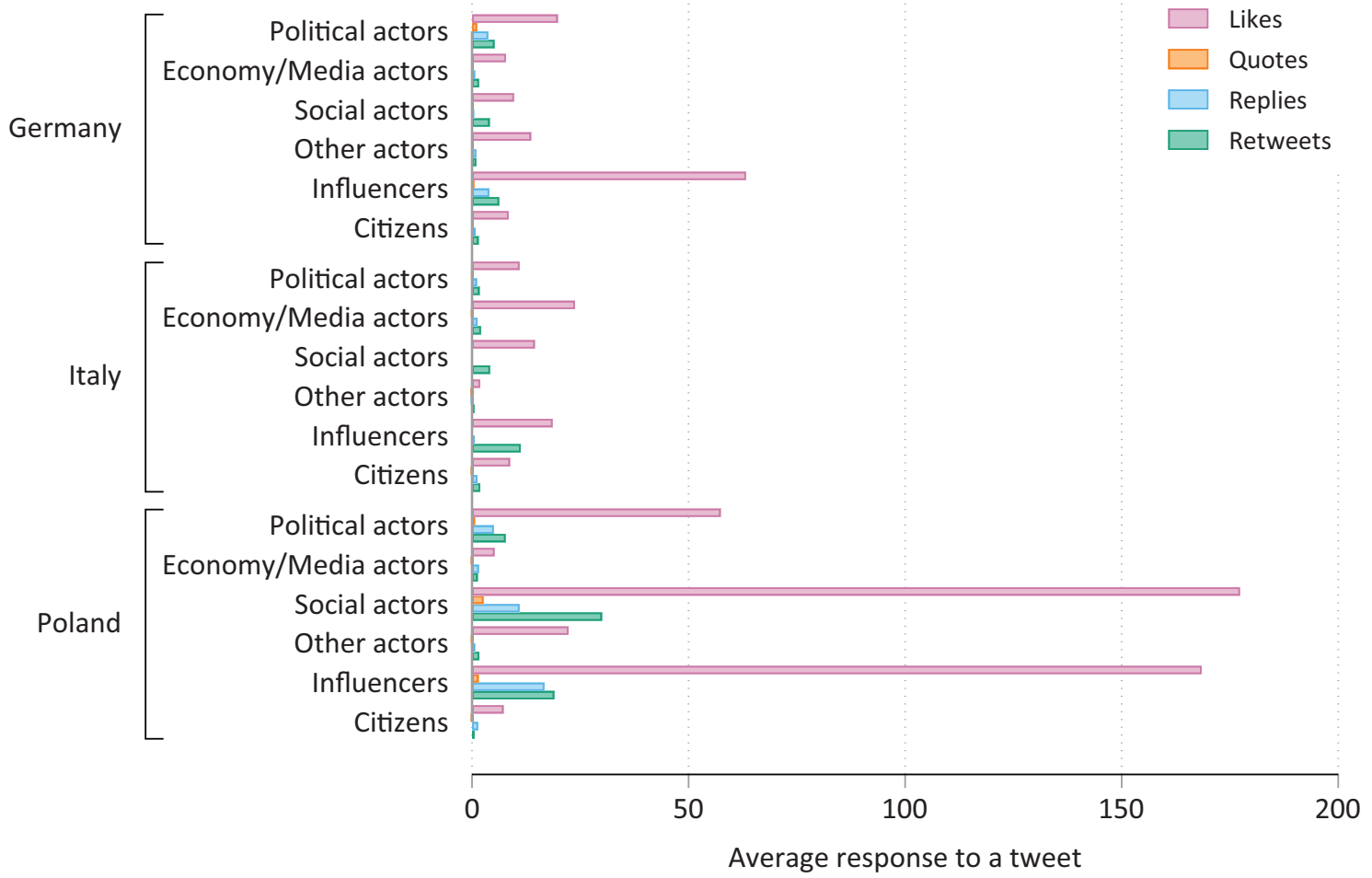

Figure 6. Levels of engagement and Twitter interactions of the audience across the three cases. 
might depend on the Twitter algorithm which structures the timeline of your follower and whether they can see what the user liked. The most valuable finding is that, on average, a higher level of political engagement creates more retweets and replies than less politically engaged tweets. Such highly engaging tweets contain criticism, calls for action, and demands of certain rights. These tweets may then lead to support (most probably as likes or retweets) or contestation by other users.

The previous two-mode networks demonstrated that political and societal actors tweet about various gender equality-related issues. On average, those tweets also receive a lot of attention-particularly in the Polish case (see Figure 7). In contrast, citizens are rather active on Twitter but hardly interacting with other Twitter users. Also noteworthy is that social media influencers, celebrities, and bloggers receive many interactions, especially in terms of likes and retweets, despite their relatively marginal appearance in the three networks. In Poland, social actors, and in Italy economic and media actors also get a comparable amount of attention. Hence, there seems to be a hierarchy of attention, with prominent actors reaching out with a few tweets while the main bulk of the debate carried out by citizens remains rather unresponded to.

\section{Conclusion}

The article analyses the public Twitter debate on the value of gender equality in Germany, Italy, and Poland during the IWD mobilization of March 2021. On the one hand, we look at how a core democratic value-gender equality-is discussed in social media, by whom, and to what extent we identify similar online debates in the three countries. On the other hand, we examine how different actors and citizens, in particular, engage in such social media debates. In addition, the article explores the possibilities and limitations of a multi-method approach and cross-country social media comparison.

Three main results stand out. First, the online mobilization on IWD is rather weakly transnationalized. The national Twitter discourses are segmented and mainly linked by the official English campaigning hashtags such as \#iwd2021 or \#internationalwomensday. Our cases also differ in their engagement level and positioning on issues: While the German Twitter public was the most politically engaged and supportive of gender equality, most Polish tweets were acclamatory and indifferent to the value. Moreover, there is only a weak similarity of issue attention across the three cases. Tweets in support of equal rights for women and raising feminist issues (in Germany and Italy) resonate most strongly across the countries. Interestingly, there are no issue references to the EU or the European policies in our sample, underlining the nationally segmented Twitter discourse structure.

Second, the most striking similarity across the cases is that citizens engage heavily on Twitter. Regarding equal rights, they focus on the apolitical and celebratory aspects of IWD and less on specific issues (this is most pronounced in Polish Twitter). Similarly, those who marginally contest the value do so in a mocking or dismissive manner of attacking feminism and employing

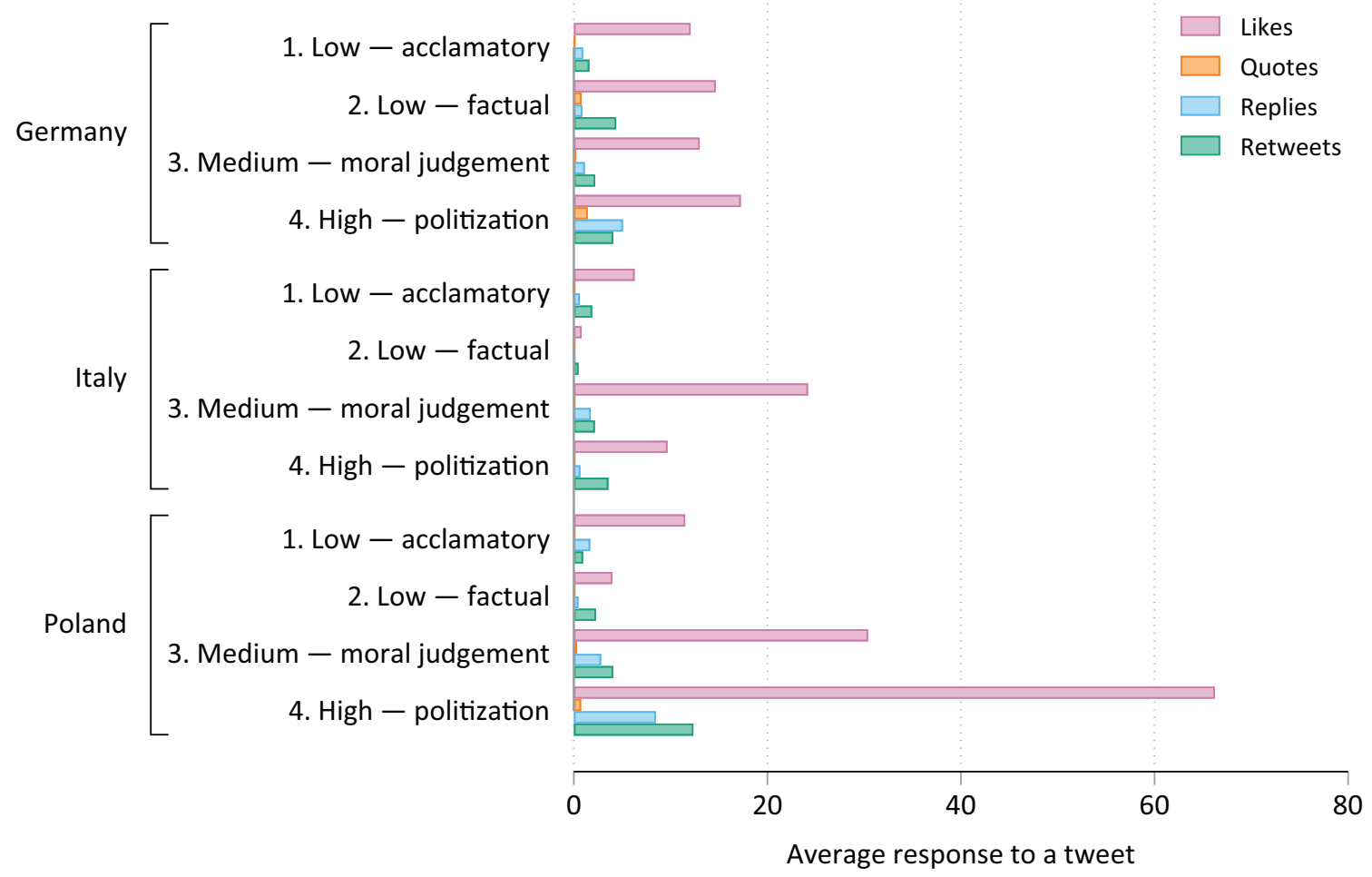

Figure 7. Levels of Twitter audience interactions by actor type in each country. 
"gender ideology" frames, instead of raising debates on specific issues. Institutionalized actors tweet about gender equality-related issues with a more moral and political stance, criticizing discriminatory practices and demanding gender policy reforms.

Third, Twitter interactions reflect differences in the levels of engagement between the actors. While citizens are strongly represented in the actor-issue networks, their tweets get fewer reactions than tweets from institutional actors. The main explanation is the stark difference in numbers of followers between citizens and institutional actors which in turn creates more visibility for tweets and leads to more reactions. The high number of Twitter reactions for influencers and celebrities stands in contrast to their less central position in the actor-issue networks. This confirms previous studies on the elite structure of social media and that only a few Twitter users are very visible in public and create (issue) attention. In this sense, our findings resemble, to some extent, results from studies of the offline public sphere, which demonstrate that political and societal actors set the public agenda. A minor additional explanation might be that many tweets from citizens that we captured with our keyword-oriented data collection are not intended to mobilize and create attention for the overall IWD campaign. This points towards different uses and engagements of Twitter users that should be further explored.

Our multi-method and cross-country approach to social media demonstrates advantages in how to examine social media data. The research design employs quantitative hashtag analysis and qualitative coding as well as discourse network methodology and content analysis. The first combination allows for a broader transnational as well as an in-depth look into national social media use patterns; the second reveals discrepancy of actors' centralities in discourse network and their influence on social media in terms of engagement and Twitter interactions. The comparative social media research design enables us to look beyond a single country or hashtag. Instead, we use country-specific keywords and hashtags that capture a broader spectrum of the debates and allow a more context-sensitive approach towards the analysis on social media platforms. In this way, we are able to study national social media discourses outside the US and English-speaking countries and capture political engagement by citizens that goes beyond the (professional) use of hashtags by NGOs and political parties.

However, this approach relied heavily on the knowledge of the national contexts by the authors. The data collection and coding of the text material were also very time-consuming. The relevant keywords had to be identified for each national context and an intersubjective meaning of the different code categories had to be established to assure valid results, especially as applied to the often relatively short tweets. In this regard, studying national social media discourses poses some methodological limitations. One such obstacle was the country selection, strongly affected by the size and primary language of the country. A small post-communist country, Lithuania, was included in our initial proposal for this study, but the Twitter debate on the IWD 2021 in Lithuanian was very marginal and made it impossible to analyse. At the same time, selecting Ireland or Spain as potential interesting cases created data collection problems due to their national languages being spoken in multiple countries, and using a geo-location filter only for those countries would have questioned the data comparability. Thus, whilst our main finding stresses the importance of national context for social media debates and questions the assumption of their transnationalization, collecting cross-country social media data remains a challenge.

Future studies should nonetheless explore this methodological task by comparing different data collection strategies for cross-country comparisons in order to systematically analyse country differences as well as examine the transnationalization hypothesis. Additionally, it might be worth analysing how democratic values such as gender equality resonate across social media platforms and to what extent citizens might engage on these platforms differently. More research might also be needed to explore other important factors involved in gender equality discourse on Twitter, such as gender or specific political/social affiliation of the Twitter users. We decided not to imply either the former or the latter from the user profiles, especially in such ethically sensitive subject matter as the actor's gender identity. Political orientation was also not always explicitly stated and would have questioned the validity of our coding.

In comparison to previous studies on anti-gender campaigns in Europe, our findings show a relatively positive (or at least neutral) tone of online debates on gender equality. This might also be a result of the time framework around IWD, probably a rather favourable context to express support for gender equality. However, the high number of tweets-especially from citizens-which express indifference to the value and issue shows that the IWD is rather understood as an apolitical event with low mobilization potential.

\section{Acknowledgments}

We would like to thank the participants of the panel "Populism, Anti-populism and Collective identity" and in particular Francesca Foe and Carlo Ruzza at the SISP Conference 2021 for constructive feedback as well as the anonymous reviewers and editors for their suggestions and comments on previous versions of our manuscript. We gratefully acknowledge funding from the Volkswagen Foundation project "Value conflicts in a differentiated Europe: The impact of digital media on value polarization (ValCon)."

\section{Conflict of Interests}

The authors declare no conflict of interests. 


\section{Supplementary Material}

Supplementary material for this article is available online in the format provided by the authors (unedited).

\section{References}

Akaliyski, P., \& Welzel, C. (2020). Clashing values: Supranational identities, geopolitical rivalry and Europe's growing cultural divide. Journal of Cross-Cultural Psychology, 51(9), 740-762. https://doi.org/10.1177/ 0022022120956716

Akaliyski, P., Welzel, C., \& Hien, J. (2021). A community of shared values? Dimensions and dynamics of cultural integration in the European Union. Journal of European Integration. Advance online publication. https://doi.org/10.1080/07036337.2021.1956915

Bastian, M., Heymann, S., \& Jacomy, M. (2009). Gephi: An open source software for exploring and manipulating networks. Proceedings of the International AAAl Conference on Web and Social Media, 3(1), 361-362. https://ojs.aaai.org/index.php/ICWSM/ article/view/13937

Benoit, K., Watanabe, K., Wang, H., Nulty, P., Obeng, A., Müller, S., \& Matsuo, A. (2018). quanteda: An R package for the quantitative analysis of textual data. Journal of Open Source Software, 3(30), Article 774. https://doi.org/10.21105/joss.00774

Blondel, V. D., Guillaume, J.-L., Lambiotte, R., \& Lefebvre, E. (2008). Fast unfolding of communities in large networks. Journal of Statistical Mechanics: Theory and Experiment, 2008(10), Article P10008. https:// doi.org/10.1088/1742-5468/2008/10/P10008

Borgatti, S. P., \& Everett, M. G. (1997). Network analysis of 2-mode data. Social Networks, 19(3), 243-269. https://doi.org/10.1016/S0378-8733(96)00301-2

Bossetta, M., Dutceac Segesten, A., \& Trenz, H.-J. (2017). Engaging with European politics through Twitter and Facebook: Participation beyond the national? In $\mathrm{M}$. Barisione \& A. Michailidou (Eds.), Social media and European politics (pp. 53-76). Palgrave Macmillan. https://doi.org/10.1057/978-1-137-59890-5_3

Bossner, F., \& Nagel, M. (2020). Discourse networks and dual screening: Analyzing roles, content and motivations in political Twitter conversations. Politics and Governance, 8(2), 311-325. https://doi.org/ 10.17645/pag.v8i2.2573

Cichowski, R. A. (2013). Legal mobilization, transnational activism, and gender equality in the EU. Canadian Journal of Law and Society/Revue Canadienne Droit et Société, 28(2), 209-227. https://doi.org/10.1017/ cls.2013.22

Czymara, C. S., Langenkamp, A., \& Cano, T. (2021). Cause for concerns: Gender inequality in experiencing the Covid-19 lockdown in Germany. European Societies, 23(Suppl. 1), S68-S81. https://doi.org/ 10.1080/14616696.2020.1808692

Dahlgren, P. (2013). The political web: Media, participa- tion and alternative democracy. Palgrave Macmillan. de Wilde, P., Rasch, A., \& Bossetta, M. (2022). Analyzing citizen engagement with European politics on social media. Politics and Governance, 10(1), 90-96.

Drüeke, R., \& Zobl, E. (2016). Online feminist protest against sexism: The German-language hashtag \#aufschrei. Feminist Media Studies, 16(1), 35-54. https:// doi.org/10.1080/14680777.2015.1093071

European Institute for Gender Equality. (2020). Gender equality index. https://eige.europa.eu/genderequality-index/2020

Froio, C., \& Ganesh, B. (2019). The transnationalisation of far right discourse on Twitter: Issues and actors that cross borders in Western European democracies. European Societies, 21(4), 513-539. https://doi.org/ 10.1080/14616696.2018.1494295

Gerhards, J. (2014). Cultural overstretch: Differences between old and new member states of the EU and Turkey. Routledge.

Givskov, C., \& Trenz, H.-J. (2014). Civic engagement through mainstream online newspapers: Possibilities and shortcomings. MedieKultur: Journal of Media and Communication Research, 30(56), 44-60. https://doi.org/10.7146/mediekultur.v30i56.16969

Heyd, T., \& Puschmann, C. (2017). Hashtagging and functional shift: Adaptation and appropriation of the \#. Journal of Pragmatics, 116, 51-63. https://doi.org/ 10.1016/j.pragma.2016.12.004

Hjarvard, S., Mortensen, M., \& Eskjær, M. F. (2015). Introduction: Three dynamics of mediatized conflicts. In M. F. Eskjær, S. Hjarvard, \& M. Mortensen (Eds.), The dynamics of mediatized conflicts (pp. 1-27). Peter Lang. https://vbn.aau.dk/en/publications/ introduction-three-dynamics-of-mediatizedconflicts

Jackson, S. J., Bailey, M., \& Foucault Welles, B. (2020). \#HashtagActivism: Networks of race and gender justice. The MIT Press. https://doi.org/10.7551/ mitpress/10858.001.0001

Kaiser, S. (2020). Politische Männlichkeit: Wie Incels, Fundamentalisten und Autoritäre für das Patriarchat mobilmachen [Political masculinity: How incels, fundamentalists and authoritarians mobilize for patriarchy]. Suhrkamp.

Knüpfer, C., Hoffmann, M., \& Voskresenskii, V. (2020). Hijacking MeToo: Transnational dynamics and networked frame contestation on the far right in the case of the "120 decibels" campaign. Information, Communication \& Society. Advance online publication. https://doi.org/10.1080/1369118X.2020.1822904

Korolczuk, E., \& Graff, A. (2018). Gender as "Ebola from Brussels": The anticolonial frame and the rise of illiberal populism. Signs: Journal of Women in Culture and Society, 43(4), 797-821. https://doi.org/ 10.1086/696691

Köttig, M., Bitzan, R., \& Pető, A. (Eds.). (2017). Gender and far right politics in Europe. Palgrave Macmillan.

Kováts, E. (2017). The emergence of powerful anti- 
gender movements in Europe and the crisis of liberal democracy. In M. Köttig, R. Bitzan, \& A. Petö (Eds.), Gender and far right politics in Europe (pp. 175-189). Palgrave Macmillan. https://doi.org/10.1007/978-3319-43533-6_12

Kuhar, R., \& Paternotte, D. (Eds.). (2018). Anti-gender campaigns in Europe: Mobilizing against equality. Rowman \& Littlefield International.

Leifeld, P. (2016). Discourse network analysis: Policy debates as dynamic networks. In J. N. Victor, A. H. Montgomery, \& M. Lubell (Eds.), The Oxford handbook of political networks. Oxford University Press. https://doi.org/10.1093/oxfordhb/9780190228217. 013.25

Leifeld, P., \& Haunss, S. (2012). Political discourse networks and the conflict over software patents in Europe. European Journal of Political Research, 51(3), 382-409. https://doi.org/10.1111/j.1475-6765. 2011.02003.x

Miller, M. L., \& Vaccari, C. (2020). Digital threats to democracy: Comparative lessons and possible remedies. The International Journal of Press/Politics, 25(3), 333-356. https://doi.org/10.1177/194016122 0922323

Pollack, M. A., \& Hafner-Burton, E. (2000). Mainstreaming gender in the European Union. Journal of European Public Policy, 7(3), 432-456. https://doi.org/ $10.1080 / 13501760050086116$

Righetti, N. (2021). The anti-gender debate on social media. A computational communication science analysis of networks, activism, and misinformation. Comunicazione politica, 22(2), 223-250. https://doi. org/10.3270/101610

Ruiz-Soler, J. (2020). European Twitter networks: Toward a transnational European public sphere? International Journal of Communication, 14, 5616-5642.

Scharff, C., Smith-Prei, C., \& Stehle, M. (2016). Digital feminisms: Transnational activism in German protest cultures. Feminist Media Studies, 16(1), 1-16. https://doi.org/10.1080/14680777.2015.1093069

Schünemann, W. J. (2020). Ready for the world? Measuring the (trans-)national quality of political issue publics on Twitter. Media and Communication, 8(4), 40-52. https://doi.org/10.17645/mac.v8i4.3162

Stier, S., Schünemann, W. J., \& Steiger, S. (2018). Of activists and gatekeepers: Temporal and structural properties of policy networks on Twitter. New Media \& Society, 20(5), 1910-1930. https://doi.org/ 10.1177/1461444817709282

Tucker, J. A., Theocharis, Y., Roberts, M. E., \& Barberá, P. (2017). From liberation to turmoil: Social media and democracy. Journal of Democracy, 28(4), 46-59.

Verloo, M., \& Lombardo, E. (2007). Contested gender equality and policy variety in Europe: Introducing a critical frame analysis approach. In M. Verloo (Ed.), Multiple meanings of gender equality: A critical frame analysis of gender policies in Europe (pp. 21-46). Central European University Press.

Wallaschek, S., Starke, C., \& Brüning, C. (2020). Solidarity in the public sphere: A discourse network analysis of German newspapers (2008-2017). Politics and Governance, 8(2), 257-271. https://doi.org/10.17645/ pag.v8i2.2609

Willem, C., \& Tortajada, I. (2021). Gender, voice and online space: Expressions of feminism on social media in Spain. Media and Communication, 9(2), 62-71. https://doi.org/10.17645/mac.v9i2.3851

Wobbe, T., \& Biermann, I. (2009). Von Rom nach Amsterdam: Die Metamorphosen des Geschlechts in der Europäischen Union [From Rome to Amsterdam: The metamorphoses of gender in the European Union]. VS.

Zoch, G., Bächmann, A.-C., \& Vicari, B. (2021). Who cares when care closes? Care-arrangements and parental working conditions during the Covid-19 pandemic in Germany. European Societies, 23(Suppl. 1), S576S588. https://doi.org/10.1080/14616696.2020. 1832700

\section{About the Authors}

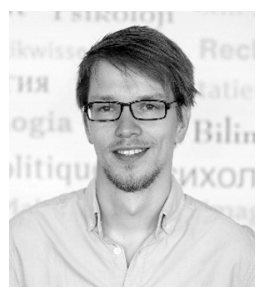

Stefan Wallaschek is post-doctoral researcher in the international research project "Value conflicts in a differentiated Europe: The impact of digital media on value polarization (ValCon)" at the EuropaUniversität Flensburg (Germany). He received his PhD from the University of Bremen in 2019 and his research interests include European politics, political (online) communication, European political sociology, network analysis, as well as the study of solidarity.

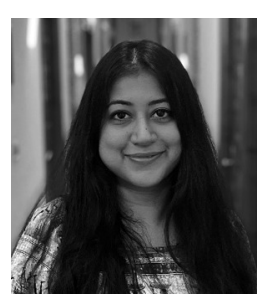

Kavyanjali Kaushik is a PhD student at University Carlos III of Madrid (Spain) and a doctoral researcher at the project "Value conflicts in a differentiated Europe: The impact of digital media on value polarization (ValCon)." Her research interests lie at the intersection of social movements, political parties, and media, with a focus on mobilisation for far right and exclusionary national identity. She received a master's in social sciences from the same university, and has worked in national and international news organizations in India, such as Reuters, CNN-News18, and India Today. 

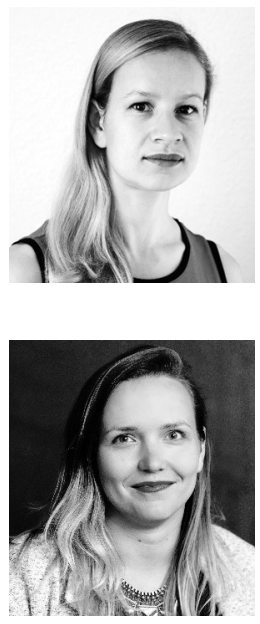

Aleksandra Sojka is assistant professor and a Juan de la Cierva-Incorporación fellow at the Department of Social Sciences, University Carlos III of Madrid. In the past, she has been a visiting scholar at the Center for European Studies (CES) at Harvard University (2016-2017). Her principal research interests lie in the field of political sociology of European integration and globalization, with a focus on political identities and attitudes.

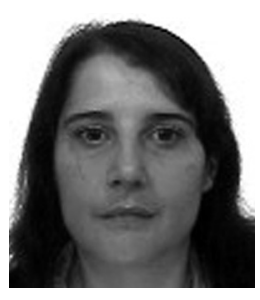

Giuliana Sorci is post-doctoral research fellow in the project "Value conflicts in a differentiated Europe: The impact of digital media on value polarization (ValCon)" at Scuola Normale Superiore, Pisa/Florence (Italy). From 2016 to 2019 she had been a PhD student in political science at the University of Catania. Her research focuses on social movements' political communication. In particular, her research revolves around the analysis of alternative social networks as a new frontier of digital media. She carries out research in the field of Italian territorial movements.

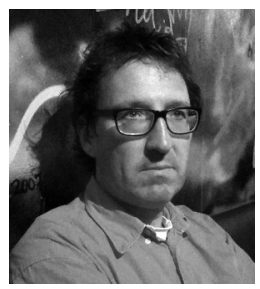

Hans-Jörg Trenz is professor of sociology of culture and communication at Scuola Normale Superiore in Pisa/Florence. He specialises in cultural and political sociology of European integration.

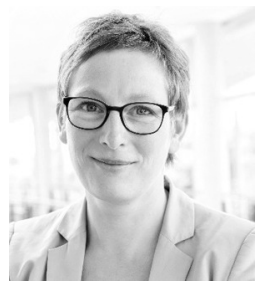

Monika Eigmüller is professor of sociology at the Europa-Universität Flensburg and director of the Interdisciplinary Centre for European Studies (ICES). In her research she deals with various fields of sociology of European integration. Main topics of interest are value conflicts and social inequality in the EU member states as well as EU social policy. Her latest book on Sozialraum Europa (Springer) has been published in 2021. 